\title{
ENGINEERING INSTRUCTORS AND THEIR TEACHING GOALS, Teaching Practices and ConcePtions of StUdent LEARNING IN UNDERGRADUATE EDUCATION
}

\author{
Lisa Romkey \\ University of Toronto \\ lisa.romkey@utoronto.ca
}

\begin{abstract}
This paper shares the results of a multiinstitutional study examining the teaching goals and practices of engineering instructors. Through both a survey and a set of interviews, engineering instructors at four institutions in Ontario were invited to share their key teaching and learning goals, teaching philosophy, and the use of teaching and learning activities in the teaching of undergraduate engineering students.

Engineering instructors shared a surprising diversity of teaching goals and practices, and through a discussion of powerful teaching activities, a set of conceptualizations around student learning emerged, ordered in decreasing prominence: Students learn through: (1) making realworld connections; (2) application of concepts; (3) interaction with the instructor; (4) interaction between students; (5) independence and ownership and (6) listening to what the professor says and does.

These views are all reflected in the diversity of learning theories available in the literature, and in particular situated learning theory, but an understanding of these specific conceptualizations, articulated by engineering instructors, can be used to better support engineering instructors in their teaching, and in the development of new curricular initiatives in undergraduate engineering education. This work expands on the existing literature on teaching in higher education and teaching practices in engineering.
\end{abstract}

Keywords: Pedagogy, Teaching, Learning, Curriculum, Qualitative Methods

\section{INTRODUCTION AND BACKGROUND LITERATURE}

This research is part of a multi-institutional study on the teaching goals and practices of engineering instructors related to the relationship between engineering, society and the environment. To enable an understanding of engineering course instructor views and practices in this area, an investigation of their more general teaching and learning goals and practices was necessary. Although this work was originally designed to support a different set of research questions, it has utility as stand-alone work, providing a useful overview of views on teaching and learning in the engineering undergraduate program professoriate.

This work builds on existing literature in both engineering education and higher education more broadly on faculty identity, and the teaching goals and practices of university instructors. In higher education, several models have been proposed to describe faculty members as teachers and their approach to teaching. For example, Robertson [18] described three stages of teacher development in professors: egocentricism, where the focus is on the teacher's content mastery, using "received" modes of teaching; aliocentricism, in which the professor is a facilitator of learning; and systemocentrism, which represents the teacher's inner life interacting with the inner life of the learner.

Martin et al [9] examined different approaches used by university instructors, and found that teaching intentions ranged from the transfer of information, to a focus on the student changing their conceptions of the subject matter. This was echoed in a similar study by Trigwell and Prosser [20]. Martin et al also looked specifically at the ways taught subject matter is contextualized - for example, as it's represented in the external world; as it's represented in the external world in context; understanding of the subject matter in relation to the discipline; and understanding of the subject matter in relation to professional practice, for example. These different conceptions can result in different teaching practices.

Samuelowicz and Bain [19] used the perspectives of 39 university instructors to develop seven orientations related to their beliefs about teaching and learning. The first three orientations were considered teacher-centered orientations: imparting information, transmitting structured knowledge, and providing and facilitating understanding. The remaining four orientations were considered learner centered, and included helping students develop expertise, preventing misunderstandings, negotiating understanding, 
and encouraging knowledge creation. The idea that there is a continuum of teaching conceptions and approaches ranging from 'teaching as information transmission' to 'teaching as supporting knowledge construction' is demonstrated across several other studies [1]. [2], [13], [21]. Postareff et al [16] interviewed 97 university teachers and found a similar range of approaches, from "learning focused" to "content focused", but noted that some instructors used a combination of the two.

A recent review of the literature [23] examined 59 recent studies to gain an understanding of the factors that impact teacher identity in the university context. In this review, the authors identified five processes that impact teacher identity: appreciation of teaching through awards and grants; connectedness with other teachers, through shared experiences and professional networks; a sense of competence in teaching and a recognition of competence by others; commitment and responsibility to the teaching with genuine care for students; and the ability to imagine a future career trajectory as a teacher, with access to role models who have done the same. As we consider the teaching goals and practices of engineering instructors, it is important to consider the supports and enabling factors associated with teaching in universities.

There is less research on the teaching choices and approaches within undergraduate engineering programs. A small study by McKenna and Yalvac [10] characterized engineering teaching approaches by describing six strategies: (1) recognizing difficulty in learning subject matter; (2) steadily increasing complexity and forming connections between topics; (3) giving real-world examples to contextualize material; (4) using multiple representations of concepts through various levels of abstraction; (5) making personal connections with students; and (6) the encouragement of interaction between students. They found that despite the lack of formal training in teaching, the instructors discussed wellreasoned teaching strategies, teaching in their discipline, and the specific development of strategies to deal with difficult topics.

However, the study also found that the instructors interviewed didn't typically adhere to the precise definition of a learner-centered environment. Those interviewed demonstrated concern for student learning, but there was a lot of focus on what the teacher is doing, rather than what the student is doing. This finding was echoed in a study of first year engineering instructors by Van Driel et al [22], in which there was a strong commitment to student learning, but misconceptions about what a student-centered approach really was. Most instructors interviewed conceptualized their approach to teaching as an intensive relationship between the teacher and student, where the teacher must interact with the student directly on a frequent basis, with a great deal of face-to-face classroom time. A small group of the instructors involved in the study were described as student-centered, and these instructors used more student-regulated activities, where students were instructed to identify and analyze problems in a cooperative and/or self-directed manner. It's worth noting that work by Moore et al [12] demonstrated that through engagement in certain instructional practices (in this case, the rigourous use of model-eliciting activities in teaching), instructors can shift to a more student-centered view of instruction.

Identifying, framing and solving problems has long been identified as a key component of the engineering curriculum and by extension, teaching practices [7], while another study [4] found that engineering instructors focused heavily on content, which was attributed to their strong disciplinary identity. The researcher found that instructors experienced personal conflict between trying to accommodate students' needs and protecting their own professional standards in engineering. In a study on engineering instructor conceptions of student understanding, Viiri [24] acknowledged that instructors engage in a process of "transforming subject matter knowledge as such into subject matter knowledge designed for the processes of teaching and learning" (p. 353). This provides another viewpoint on how subject matter knowledge is treated and translated in the teaching process. Within mechanical engineering, two studies [5], [17] found some agreement about what the fundamentals to be taught were, but disagreement about the broader purpose of engineering and a diversity of beliefs about teaching approaches, learning goals and the nature of the engineering profession.

Further to examining instructor views on engineering as a profession, Pawly [15] found three narratives: 1) engineering is about applied science and math; 2) engineering is about solving problems; and 3) engineering is about making things. Engineering as applied science and math referred to the application of science and math to problem solving, and using that as a foundation to "do engineering". Engineering as problem solving demonstrated a human perspective, through the identification of problems defined by society, although who constituted "society" was not always made clear. These instructors felt that engineering should be useful and should help society, applying scientific knowledge and the creation of products and processes to the needs of society. Finally, "Engineering as Making Things" represents a focus on the creation of products and processes, with an emphasis on business and design. These diverse views of engineering may result in a range of teaching strategies, as instructors try to convey the spirit of engineering through their teaching.

In summary, the research on pedagogical choices in the higher education environment, and the more limited research in engineering, demonstrates a number of influencing factors. There are some key models to consider in looking at teaching in undergraduate education, most notably the different variations of "teacher as 
expert/knowledge transmitter" and "teacher as facilitator/knowledge builder". Instructors also have different views on subject matter and the best modes of guiding students to understand their discipline. The results of this study build on the existing literature by providing a more detailed exploration of the teaching goals and pedagogical choices of engineering instructors.

\section{METHODOLOGY}

The research was primarily qualitative, through an online survey $(n=180)$ and a set of semi-structured interviews $(\mathrm{n}=12)$, although the online survey included some questions that were quantitative in nature. In the survey, relevant to this paper, instructors were asked to describe their most important teaching and learning goals; they were asked to rate the frequency of use of a comprehensive set of teaching, learning and assessment activities, and they were asked to list their top 3 teaching, learning and assessment activities, with an explanation of why one of the three is particularly powerful. In the semistructured interviews, participants were asked for basic information about their teaching (for example, what do they teach, and for how long have they taught); they were asked to discuss their teaching philosophy and key goals in the teaching of undergraduate students; and to describe some of the teaching practices used to reach these goals.

There are 16 degree-granting institutions in Ontario that offer engineering programs. The online survey was deployed to all engineering instructors at 4 of these institutions, representing three major institutional types ((Major Research (Institutions A and B, as noted in the analysis), Comprehensive (Institution C) and Primarily Undergraduate (Institution D)), and diverse geographic locations within the province. All research and teaching stream faculty, adjunct and sessional instructors, retired professors who still held teaching responsibilities and graduate student instructors with full course teaching responsibilities were interviewed, representing the full teaching complement. After completion of the online survey, participants were asked to email me, as the principal investigator, if they were willing to participate in an interview. After a list of volunteers was compiled, a stratified purposeful sampling strategy was used, as described by Miles \& Huberman [11] to select interview participants, allowing for a diverse set of perspectives within a group of individuals drawn together through their identity as engineering instructors.

As described by Grbich [3], a process of thematic coding, using segmentation, categorization and re-linking (prior to a final interpretation) was used to analyze the data. First, I conducted multiple reviews of each segment of data (text), whether it was from the qualitative survey questions or interviews, noting down possible themes. I also utilized a memo-writing process, to help guide the process of theorizing as I reviewed the data. The identified themes were listed and categorized where possible. Then, a review across the categories was conducted, to seek over-arching themes and patterns.

\section{RESULTS}

180 instructors participated in the survey, representing a diversity of academic disciplines, position types and years of experience in teaching. A brief summary of demographics is offered in Table 1:

\begin{tabular}{|c|c|}
\hline Gender & $\begin{array}{l}21 \% \text { Identified as female } \\
79 \% \text { Identified as male }\end{array}$ \\
\hline Position & $\begin{array}{l}\text { 57\% Research Stream } \\
\text { 23.5\% Teaching Stream/Lecturer } \\
\text { 15.5\% Sessional or Adjunct } \\
\text { 1.5\% Graduate Students/Post Doc } \\
\text { 2.5\% No indication given }\end{array}$ \\
\hline Experience & Mean of 15 years experience \\
\hline Home dept & $\begin{array}{l}15 \% \text { Mining, Civil, Environmental } \\
19 \% \text { Electrical \& Computer } \\
16 \% \text { Chemical } \\
13 \% \text { Mechanical, Industrial, Eng Mgmt } \\
12 \% \text { Math/Science } \\
3 \% \text { Social Science, Communication } \\
22 \% \text { Other }\end{array}$ \\
\hline Industry & $\begin{array}{l}85 \% \text { had some industry experience; } \\
\text { including experience as an } \\
\text { undergraduate or graduate student, } \\
\text { industry experience through short-term } \\
\text { leaves, and industry collaborations. }\end{array}$ \\
\hline
\end{tabular}

Table 1: Survey Participant Demographics

The individuals interviewed represent a diverse group of instructors, representing all major position types, several disciplinary areas within engineering, varying years teaching experience (between 2 and 40 , with a mean of 14 years) and various industry experiences. 11 of the interview participants were male and 1 was female, which is a very unfortunate under-representation of female instructors. Survey participants were asked to email the principal investigator if they were interested in an interview, and so unfortunately, this left little room for actively recruiting female participants who did not come forward. Future research should attend more specifically to the goals and practices of female instructors, to better understand their perspectives.

The results are presented in three sections: first, instructor teaching goals are discussed; then, teaching and learning practices - with a focus on instructor perceptions of the most powerful teaching and learning practices are explored; finally, engineering instructor conceptions of student learning, based on their discussion of teaching goals and practices, will be presented. 


\subsection{Teaching Goals}

Teaching and learning goals fell into one of three major categories: (1) Content-related goals ( $\mathrm{n}=108)$, (2) Skill and competency related goals $(\mathrm{n}=120)$ and $(3)$ Goals related to making connections: between the curriculum and something external, such as career goals or other learning experiences, and to a lesser extent, within the curriculum or teaching/learning experience $(\mathrm{n}=91)$. The responses, within these themes, were then coded again and are represented using a set of sub-themes, with the exception of the content-related goals, as these proved to be as diverse as the knowledge base in engineering itself. Several participants reported goals that belonged to more than one of the three major themes, and so their goals were reported under multiple themes. Thematic content analyses of interviews allowed for triangulation and corroboration of the major themes and many of the sub-themes.

\subsubsection{Teaching and Learning Goals about Content.}

The content category represents a focus on the actual disciplinary or subject-matter content taught in the course. Some instructors simply stated that, in general, subject matter was more important. For example, one instructor noted "I want my students to memorize and to be able to efficiently apply knowledge... acquired in my course", while another stated that their goal was to "promote the internalization and retention of course concepts through the use of multiple interactive learning modes inside of the classroom". In some cases, instructors positioned content against other priorities; for example, one instructor noted that they "would like the students to understand the basic concepts rather than the learning techniques", and another seemingly positioned cognitive and affective learning against one another, noting that "It's been said that more satisfying than knowledge itself is the FEELING of knowing but I want my students to discovery that there is nothing more satisfying than ACTUAL knowledge."

Some instructors expressed a desire to have their students understand the central or core concepts associated with their discipline or subject area; for example, "I want the students to be highly competent in the main (most important) aspects of the courses I teach". Michael, a mechanical engineering instructor from Institution A noted that "over the years I have tended to simplify these courses. I have tried to focus on fewer concepts and try to get the students to learn those better than trying to ram my way through a prescribed curriculum". Other instructors focused on their own specific subject matter in their responses. As noted earlier, these responses were as diverse as the subject matter within engineering, for example, "Describe key aspects of the technologies associated with energy systems"; "Understand the interaction between hardware and software" and "Comprehensively proficient in the fundamentals of rock mechanics"
James (Electrical Engineering, Institution A, Interview Response) described the importance of students being able to learn on their own, stating "I think that we can open the door and they really have to make sure that through their own efforts that they learn the material". This is particularly important in considering that students will need to learn beyond the four years of a university degree. David (Chemical Engineering, Institution B, Interview Response) noted "we've got four years - there's such an enormous body of stuff and each individual has a different idea of what's important. There's absolutely no way we can communicate other than... a cursory exposure".

\subsubsection{Teaching and Learning Goals about Skills and Competencies.}

The "Skills and Competencies" category spoke to various abilities that transcend disciplines. The most common skills noted were problem analysis and quantitative analysis. Problem analysis included problem framing: "the most important single learning goal is to take a posed situation and formulate from it the problem to be solved"; and a focus on interpretation and analysis: "To be able to understand what they're doing and why. To be able to interpret a result and/or discuss a method rather than simply present an answer". Another instructor emphasized the consideration of multiple approaches, stating "I try to engage students in the questions of "what to do" before engaging in the questions of "how to do". For any engineering problem, there are typically alternative analysis approaches and techniques." Quantitative analysis, often used to support problem solving, was cited frequently by the instructors. For example, instructor goals in this category included "develop ability for quantitative analysis of engineering phenomena"; "develop proficiency in data analysis"; and "critically analyze quantitative data and integrate numerous quantitative measurements to make decisions".

Critical thinking also emerged as a particularly salient theme in the analysis of instructor goals; for example, "In environmental engineering I want my students to be critical thinkers and analyzers" and "develop the ability to reason logically and recognize the potential errors in a given argument." A few instructors applied critical thinking to problem solving; for example: "I aim to make students think logically and critically about problems. I emphasize rigorous first principles in solving problems, and deemphasize heuristic recipe-based solutions."; and "I want my students to retain an understanding of problem decomposition and logical reasoning." The instructors also hoped the students would develop an understanding of why some of the methods work, for example, "I want the students to understand the idea and the principles behind the mathematical tools that they use, not just following recipes to reproduce calculations." Some instructors wanted students to simply be able to detect the validity of 
something, or "(know) how to establish for themselves whether something is true or not true".

Design and related competencies were the third most cited skill/competency. In some cases, the instructors took a holistic view of design education; for example, one instructor suggested they wanted their students to "(build) an understanding of a problem, develop a design (solution) for the problem, then build, test, and run the solution.", while another instructor wanted their students to "be able to take a system specification and available tools and design a system and estimate its performance". In some cases, instructors focused on a specific aspect of design, for example, "I want them...to understand the fundamentals behind the design so that they can apply what they've learned to solve new or different problems" (civil engineering, institution c, interview response); "Understand trade-offs in the design"; and "I want my students to understand...the importance of considering human capabilities and limitations in the design of systems". Instructors also cited goals related to skills and competencies that are often coupled with design, for example communication skills and creativity.

\subsubsection{Teaching and Learning Goals about Making Connections.}

The "Making Connections" category describes the goals relevant to drawing connections, primarily between the curriculum and the real world, or between the learning experience and the current or future lives of the students. The notion of connecting theory and practice was a common theme; for example, "I want my students to have a strong connection between theory and practice - to understand the fundamental concepts and then to use them with real practice.". Some instructors connected specific subject matter to real-world problems, for example: I want my students to see that physics has direct connections to real world problems.". Some instructors prioritized a focus on the "big picture"; for example, "Probably the most important thing is how does it tie in? Why is it relevant? How does it tie in, not just to the bigger ideas of this course but to the bigger ideas of the other courses they're taking and the field itself?" (Phillip, materials engineering, institution A, interview response). Some instructors specifically cited technical content and potential industry applications, for example, "relationships between core courses (i.e. heat transfer) and applications in the industry (i.e. industrial cooler or oven design)." Several instructors wanted their students to make connections to, and be generally prepared for, their career. In some cases, it was simply a hope that the students will use and apply their knowledge in their working life, for example, "I want my students to learn skills that are directly relevant to industry and that will enable them to take on senior design and management roles in their careers". Instructors also spoke to the importance of motivation and engagement; a connection between the learning and "self". For example, instructors noted: "I want my students to be engaged by the course content"; "I hope my students come away with a (sometimes renewed) interest in these topics"; and "I want them to leave the course excited about the new knowledge they now have".

\subsection{Teaching Practices}

Instructors participating in the survey were asked to name their three most powerful teaching activities, and describe why one of their top activities was powerful. The most powerful, based on frequency, were: (1) lectures (both traditional and traditional with active learning activities); (2) engineering problem solving as an instructional activity; (3) teaching practices with real world engagement; and (4) student-lead learning.

In examining the instructor survey responses about lectures, some of the responses were qualified - for example: "self-contained, clear, organized series of lectures". These instructors, in their justification of a powerful activity, often prioritized the view of the instructor, for example, "the student learns not only the topics of the course, but the value system of the instructor"; or the content: "Lectures (are) the most powerful manner of teaching highly advanced technical material to senior engineering students, especially when a key goal of the course is the imparting of a fundamental understanding of the subject". Some instructors spoke to interactive activities that take place in the context of a lecture. The structure and function of in-class interactive activities - often described as "active learning" in higher education - can be quite diverse. In the case of the engineering instructors, responses included "actively solicit questions from students during lecture" and "pose questions to students during lecture". However, a variety of other activities were also included, such as "one-minute writing exercises within class to focus thinking or generate responses"; "using lecture to do what texts, etc cannot: demonstration, questioning, interaction, motivation, reassurance" ; "short individual active learning activities in lecture (or tutorial), such as "solve this problem independently", and "small group discussion leading to larger group discussion".

Some instructors using traditional methods cited different teaching activities that, again, typically occur in lecture, but demonstrated a more sophisticated understanding of student learning. For example, "A focus on themes showing students the similarities among apparently different concepts"; "explaining cause and effect"; "inductive and deductive reasoning with examples". One instructor who cited specific tactics from the context of the lecture noted that "lectures should bring things, ideas, illustrations, principles, support and motivation to the students - things that often can only be done on the fly, and with emotional intelligence lacking in our other resources." All told, it's important to remember 
that the use of traditional teaching methods does not mean that the instructor is not considering student learning and the specific ways of improving it; in the case of higher education, there is innovation within tradition.

Problem solving and analysis was the second most frequently cited powerful activity. Some instructors qualified "problem solving" with a more specific description of what they suggest are useful problems - such as "Wicked problems - students need to be challenged with messy problems"; "problems to which they don't have a readily accessible process to solve" and "problem sets, ideally with some collaborative and/or controversial component".

Reflective of the instructor goals, practices with realworld engagement were cited by instructors as being particularly powerful. As noted by James (Electrical Engineering, Institution A, Interview Response), for example, a concept like integration in the complex plane may seem abstract, but when the students see "little robots running around in a self-controlled automated fashion it's like, oh wow, that's pretty amazing...the theory does lead to...some specific applications". Instructors focused on activities in which students made connections to real-world examples or engagement, and/or student driven examples or problem framing that allows students to make their own real-world connections. For example, instructors noted the importance of "connections - students must be constantly reminded that their course material connects to the real world"; "presentation of industrybased problems to give context to material at hand"; and "real world projects with real world clients", demonstrating the range of activities utilized with varying levels of student engagement. The instructors also discussed the engagement of real-world actors as a powerful teaching activity, through collaborations with different groups and individuals, for example: "external validation of students results from industry experts"; and "Bring in users of engineering designs to explain problems they experience". Finally, case studies were described by the instructors as another powerful example of an activity with a high level of student engagement that engages a "real-world" context.

The final most powerful teaching activities were examples of students taking the lead through hands-on learning activities. In addition to problem solving and realworld activities discussed above, instructors named practices such as projects, laboratories, collaborative learning activities (that take place outside of class) and writing. In the discussion of projects, some instructors specified the type; for example, "non-specified design projects" and "design reports/evaluations that require justification of their choices" . Collaborative learning activities included assignments that emphasized a group or collaborative focus; for example, "group assignments"; and "prepared group debates". Instructors also discussed activities that were genuinely student- driven; activities that give students some independence and control over their learning. For example, "(use of) studentsourced ideas and concepts"; "group teaching (group prepares outside of class)"; and "peer review and feedback". When discussing student-driven activities, instructors tended to note the value of the student helping to direct the focus or select the topic, the importance of student ownership and responsibility, the ability to immediately identify gaps or weaknesses in understanding, and tapping into what the students already know (and don't know).

\subsection{Conceptions of Student Learning}

Although the instructors were not asked specifically about student learning, throughout the survey and interview data on teaching goals and practices, there was an emphasis on ideas around student learning - more specifically, what needs to happen for student learning to happen, from the instructor perspective? The most salient themes are described below:

\subsubsection{Students Learn Through Real-World Connections.}

Many instructors indicated that learning takes place when the material is contextualized in real world problems and examples. For example, one instructor described the advantage of moving beyond a theoretical approach, suggesting that problem-based learning "provides a venue to discuss nuances and conflicting perspectives that may not be able to be presented in a purely theoretical approach"

Another instructor, for example, described the link to motivation, stating that "the concepts (electromagnetic fields and waves), require them to utilize mathematics and physics extensively, so using real-world examples motivates students to make this investment by showing them how the investment is useful in real life".

\subsubsection{Students Learn When They Apply their Learning.}

Instructors linked learning to application, often through problem solving; for example, "My course has a strong analytical/mathematical component; students need to complete a number of problem sets in order to appreciate how these mathematical tools can be brought to bear on the engineering questions at hand". Some instructors discussed the use of in-class activities for immediate application, for example, the use of active learning questions "forces the student to apply what was just learned (and) gives me instant feedback on how the concept was grasped". Another instructor stated "I see the lecture time as a time where I will show them how to do 
things and motivate them to do (things) by themselves, but definitely the most important part in the learning process is what the student (does) on his own". In a few cases, 'learning through doing' happened in the laboratory, which provided "an interactive way to learn and understand complex physical concepts and how they are applied in engineering". In other cases, design or other projects allow for this application of what they've learned; for example, "Design projects are important in the area of human factors design because it is a method-based course that requires skill development and application of methods. This is difficult to learn in lectures or assess on an exam."

\subsubsection{Students Learn through Interaction with the Instructor.}

Interaction can allow for a dialogue where the student shows the instructor what they know, and the instructor provides feedback or clarification of understanding or a concept; for example, "It takes only a few minutes with a student to determine where their problems lie, and what techniques they can try in order to fix it" . Another instructor noted the value of making themselves accessible, stating "I try my best to be accessible and open to questions. I do whatever it takes to lower the barrier for students to ask questions." One instructor noted the importance of one-on-one communication, sharing "whether personal or through an electronic medium is where learning occurs best". Some instructors spoke to specific modes of interaction in lecture, for example, one noted "I wait and do not continue until I get feedback or another answer", while another shared that they "actively (solicited) questions - which engages and empowers students; (and) allows one to establish (a) more collegial relationship based on mutual respect.". Finally, a couple of instructors in particular described a process - in some ways, a gentle dance between the professor and the students that leads to learning. One instructor noted that their effective approach involved "presenting students with a problem, breaking it down, asking questions, letting them ask questions, and proceeding slowly towards a solution".

\subsubsection{Students Learn from Each Other.}

These instructors reflected on the importance of having students learn from each other, which can happen in a diversity of settings. For example, sometimes this is through a highly structured activity, other times it's more informal. Sometimes this is a through a team-based project, where they must "develop relational skills" and "understand group dynamics". One instructor spoke to the value of seeing the perspective of others, stating "The small problem based learning exposes students to different perspectives about the same material and forces examination of what students think they know." A biomedical professor provided a particularly eloquent description of the value of learning with others, noting that no one works alone in biomedical engineering because of its complex and multi-faceted nature, and suggesting that "if they can't extract the best knowledge out of a partner and discard what is not useful then they will perform below par in the real world in this field."

Finally, instructors reflected on the students' motivation to perform in front of peers, with one instructor stating that "Expecting a student to teach another student forces the former to learn and understand the material well", as well as competition, with one instructor sharing their perspective that "the single most important driver is their competitive juices, trigger by being surrounded by people of similar age and ability and all confronted by the same hurdles to clear".

\subsubsection{Students Learn through Independence and Ownership.}

Some instructors noted the importance of independence and ownership in the learning environment. For example, one instructor noted that through a peerteaching activity in which the students had to learn something thoroughly and teach it to their peers, "the activity gives the presenting students a sense of ownership and responsibility for the content and the presentation". An instructor describing other independent learning activities stated that "Students need to take ownership of knowledge", while another shared that "when a student depends on the instructor to indicate what is right, what is wrong, the student abdicates responsibility in the teaching/learning process". Sometimes, independence is reflected in giving students a choice in what they learn about, where students can be "creative (and are) likely to learn more if they get passionate about the project", with another instructor noting that "the ownership that accompanies the project choice buys their focus".

\subsubsection{Students Learn from what the Professor Says and Does.}

Significantly fewer instructors held this perspective, but those who did followed a more traditional conception of transmission; for example, one instructor noted that lectures are "the most powerful manner of teaching highly advanced technical material to senior engineering students", without providing a specific justification of why this is. However, some instructors also provided interesting commentary on the opportunity to personalize their presentation of the content; for example, one instructor noted "(in the) lectures....the student learns not only the topics of the course, but the value system of the instructor. Questions like "what is important? What is a detail?" are sorted out". In a few cases, lecturing gave the opportunity 
to share their personal experiences; for example, "examples to illustrate concepts (that) represent the lecturer's personal experience".

Additional themes emerged that were less prevalent for example, student learning through the integration of knowledge; through reflection or self-assessment; through assessment by the instructor; and a variety of other perspectives. Overall, this analysis of powerful teaching activities, through the lens of beliefs about student learning, once again demonstrates the diversity of thinking about teaching and learning that exists in the undergraduate engineering environment.

\section{DISCUSSION \& CONCLUSIONS}

Overall, a diversity of teaching goals and practices were found in the survey and interview data, and instructors presented a variety of ideas about student learning. The focus on subject matter was expected; students are being educated within the context of an engineering discipline and are required to build knowledge in the relevant science, engineering and mathematics concepts. A focus on disciplinary knowledge has a long history in the context of university education. Likewise, the focus on problem solving and design were expected, given the tradition of these skills as major foci in engineering education and industry and the associated accreditation requirements. However, the focus on other skills and competencies, on making connections, and on the overall variety of goals and practices, were more surprising.

As discussed in the first section, many of the studies on models of teaching in the post-secondary environment focus on different approaches with respect to the subject matter; from "transmission" to "construction (or reconstruction" of knowledge". Many of these studies focus on the content as part of a discipline, and the approaches described range from an instructor who believes their role is to transfer information to the student, to a focus on encouraging the student to challenge disciplinary conceptions and their own conceptual understanding. Certainly, a large number of instructors in this study did speak to their expectations around conceptual understanding (and in some cases, the transmission of content), but much of the focus was on the skills and knowledge needed in professional practice or the "real world". One way to consider the emphasis on skills and competencies in this study is that it, perhaps, demonstrates a way that the instructors take both the content and the learner into account; using skills to better navigate and explore the content, while providing the learner with something that transcends the course content and can be used in their future professional lives.

The results of Martin et al [9], which conceptualized university teaching approaches, are particularly relevant to the findings of this study. As noted in the first section, the authors looked at conceptions around the object of study; including disciplinary, real-world representation, and as related to professional practice, which incidentally map to the three major categories of teaching goals. Based on the results of this study, this framing of teaching might be useful for engineering undergraduate education in particular, which combines a strong disciplinary tradition with real-world applications and professional practice.

The research also demonstrated that instructors are building their teaching activities around a variety of conceptions of how students learn. This presents a complex teaching and learning environment that must be carefully navigated by anyone seeking to bring change to the engineering curriculum. Trying to encourage all engineering instructors to use a single approach with respect to any aspect of teaching and learning would be a challenge, and so any recommendations will need to consider the varied priorities that exist.

Finally, as noted in the results, many of the instructors surveyed and interviewed focused on the idea of making connections in their teaching - often through real-world applications, and less frequently with other courses and the personal and future professional lives of the students themselves. Engineering has long had a tradition of focusing on real-world applications, given the linkages to specific industry partners and sectors, and the profession itself. The focus on encouraging students to make connections between the subject matter and real-world applications or their future career in particular are reflective of a situated learning framework [8]. As opposed to a more traditional, transmission-oriented approach, in which knowledge is built through abstract, out-of-context experiences like lectures, situated learning engages students in authentic learning situations, which are connected to the workplace (or future workplace) or lives of the students. Learning is measured by changes in how the learner is able to participate in an already existing community [14], and is aided by mentors in the community of practice. The relevance of situated learning to engineering has been established elsewhere. For example, Johri, Olds and O'Connor [6] note the usefulness of situated learning as a lens through which to conduct research on engineering learning based on three characteristics of engineering: the use of representations, alignment with professional practice, and the emphasis on engineering design. Understanding this connection to established learning theory provides some useful guidance in thinking about supporting engineering instructors and guiding them through curriculum change, and in the case of situated learning, demonstrates the importance of developing teaching and learning activities that reflect a sense of authenticity and relevance to the profession.

\section{Acknowledgements}

I would like to acknowledge the engineering instructors who participated in this study. All procedures performed 
in studies involving human participants were in accordance with the ethical standards of the University of Toronto Research Ethics Board.

\section{References}

[1] G.S. Akerlind, "A new dimension to understanding university teaching", Teaching in Higher Education, vol. 9, no. 3, pp. 363375, 2004.

[2] M.G. Eley, "Teachers conceptions of teaching, and the making of specific decisions in planning to teach", Higher Education, vol. 51, pp. 191-214, 2006.

[3] Carol Grbich, Qualitative Data Analysis. London, UK: Sage Publications, 2007.

[4] S. Harris, "Rethinking academic identities in neo-liberal times", Teaching in Higher Education, vol. 10, no. 4, pp. 421433, 2005.

[5] A. Jenkins, "Discipline-based educational development", International Journal of Academic Development, vol. 1, no. 1, 5062, 1996.

[6] Aditya Johri, Barbara Olds \& Kevin O'Connor, "Situative frameworks for engineering learning research", in Cambridge Handbook of Engineering Education Research (pp. 47-66). Cambridge University Press, 2015

[7] D. H. Jonassen, "Engineers as Problem Solvers", in Cambridge Handbook of Engineering Education Research, A. Johri and B. M. Olds, Eds. Cambridge: Cambridge University Press, 2014, pp. 103-118.

[8] J. Lave \& E. Wenger, Situated Learning: Legitimate Periperal Participation. Cambridge, UK: Cambridge University Press, 1990.

[9] E. Martin, M. Prosser, K. Trigwell, P. Ramsden \& J. Benjamin, "What university teachers teach and how they teach it", Instructional Science, vol. 28, no. 5, pp. 387-412, 2000.

[10] A.F. McKenna \& B. Yalvac, "Characterizing engineering faculty's teaching approaches", Teaching in Higher Education, vol. 12, no. 3, pp. 405-418, 2007.

[11] M.B. Miles \& A.M. Huberman, Qualitative Data Analysis: An Expanded Sourcebook. Thousand Oaks: Sage Publications, 1994.

[12] T.J. Moore, S.S. Guzey, G.H. Roehrig, M. Stohlmann, M.S. Park, Y.R. Kim, H.L. Callender, and H.J. Teo. "Changes in Faculty Members' Instructional Beliefs while Implementing
Mode-Elicing Activities", Journal of Engineering Educaton, vol. 104, pp. 279-302, 2015.

[13] K. Murray \& R. Macdonald, "The disjunction between lecturers' conceptions of teaching and their claimed educational practice", Higher Education, vol. 33, no. 3, pp. 331-349, 1997.

[14] W.C. Newstetter \& M.D. Svinicki, "Learning theories for engineering education practice", in Cambridge Handbook of Engineering Education Research (pp. 29-46). Cambridge

[15] A. Pawley, "Universalized narratives: Patterns in how faculty members define "engineering", Journal of Engineering Education, vol. 98, no. 4, pp. 309-319, 2009.

[16] L. Postareff, N. Katajavuori, S. Lindblom-Ylanne, \& K. Trigwell, "Consonance and dissonance in descriptions of teaching of university teachers", Studies in Higher Education, vol. 33, no. 1, pp. 49-61, 2008.

[17] K.M. Quinlan, "Scholarly dimensions of academics' beliefs about engineering education", Teachers and Teaching: Theory and Practice, vol. 8, no. 1, pp. 41-64, 2002.

[18] D.L. Robertson (1999), "Professors' perspectives on their teaching: A new construct and development model", Innovative Higher Education, vol. 23, no. 4, pp. 271-294, 1999.

[19] K. Samuelowicz, \& J.D. Bain, "Revisiting academics' beliefs about teaching and learning", Higher Education, vol. 41, no. 3, pp. 299-325, 2001.

[20] K. Trigwell \& M. Prosser, "Congruence between intention and strategy in university science teachers' approaches to teaching", Higher Education, vol. 32, no. 1, pp. 77-87, 1996.

[21] K. Trigwell, M. Prosser, \& P. Taylor, "Qualitative differences

in approaches to teaching first year university science", Higher Education, vol. 27, pp. 75-84, 1994.

[22] J.H. Van Driel, N. Verloop, H.I. Van Werven \& H. Dekkers, "Teachers' craft knowledge and curriculum innovation in higher education", Higher Education, vol. 34, no. 1, pp. 105-122, 1997.

[23] Thea van Lankveld, Judith Schoonenboom, Monique Volman, Gerda Croiset \& Jos Beishuizen, "Developing a teacher identity in the university context: a systematic review of the literature", Higher Education Research \& Development, vol. 36, no. $2, \quad$ pp. $325-342, \quad 2017$.

[24] Jouni Viiri, "Engineering teachers' pedagogical content knowledge", European Journal of Engineering Education, vol 28, pp. 353-359, 2003. 